\title{
CONVOCATORIA DE JUNTA GENERAL Y MEDIOS DE COMUNICACIÓN ELECTRÓNICOS. ESPECIAL CONSIDERACIÓN DE LA PÁGINA WEB EN DERECHO ESPAÑOL Y DERECHO CHILENO
}

\author{
CALLING OF GENERAL MEETING BY ELECTRONIC MEANS. \\ SPECIAL CONSIDERATION OF WEBSITE IN SPANISH AND \\ CHILEAN LAW
}

MARÍA JESÚS BLANCO SÁNCHEZ * **

\section{RESUMEN}

Asistimos a una generalización en el uso de las nuevas tecnologías aplicadas al Derecho de sociedades. Los beneficios que aporta a la operatividad en el ejercicio de los derechos la página web como instrumento de difusión o como medio para la realización de comunicaciones entre sociedad y socios está fuera de toda duda. Será objeto de este trabajo el análisis del papel que los medios electrónicos y las nuevas tecnologías juegan en materia de convocatoria de junta general. Será hilo conductor la normativa vigente en los ordenamientos español y chileno. Tratada la cuestión con una actitud de análisis crítico se advierte la escasa utilización del medio en Derecho español y la preocupante fragmentación del Derecho societario regulador de la cuestión que nos ocupa en Chile.

\footnotetext{
* Abogada, Doctora en Derecho, Universidad Pablo de Olavide, Sevilla, España. Correo electrónico: mjblasan@acu.upo.es. ORCID: https://orcid.org/0000-0002-1196-3107.

** Este trabajo se desarrolla en el marco de una estancia de investigación llevada a cabo entre los meses de octubre y diciembre de 2019 en la Universidad de Concepción, Chile. Financiación: Beca Santander Iberoámerica.

Se ha contado con la inestimable colaboración del profesor Maximiliano Escobar Saavedra, sin cuyos ilustrativos y generosos aportes no habría llegado a estos resultados.

Artículo recibido para revisión el 22 de noviembre de 2019, y aceptado para su publicación el 12 de junio de 2021.
} 
Palabras Clave: Convocatoria, Junta general, Notificación a accionistas, Nuevas tecnologías, Página web, Derecho chileno y español.

\section{ABSTRACT}

We have seen the general use of the new technologies on company law. The benefits of them as an instrument for spreading or mean of communication between the Company and the Shareholders are unquestionable. The objective of that paper is to present the role of electronic means and new technologies with regard to calling of the shareholders' meeting in Spanish and Chilean law. The question has been treated with an attitude of critical analysis. The scarce use of the website in Spanish Law and the worrying fragmentation of corporate law regulating the issue in Chile have been noted.

Keywords: Calling, Shareholder's meeting, Shareholders notice, New Technologies, Websites, Chilean and Spanish Law.

\section{INTRODUCCIÓN}

Las implicaciones de las nuevas tecnologías influyen de manera transversal y en las múltiples y diferentes áreas y facetas del Derecho. Indudablemente también al Derecho societario. Al inicio de siglo, los profesores FERNÁNDEZ y ViCENT señalaban la falta de regulación de un fenómeno que irrumpía y planteaban soluciones operativas para el mismo, que iban desde la convocatoria de junta general por medios electrónicos o la celebración de juntas y consejos virtuales hasta la solicitud electrónica de representación. ${ }^{1}$

La dinámica del comercio internacional, que se desarrolla en el marco de un mundo globalizado teniendo como protagonistas fundamentales a las sociedades mercantiles, requiere del análisis comparado de la materia. Este concreto estudio se realiza en el marco de una estancia de investigación en la Universidad de Concepción, Chile. El contacto que esta investigadora ha tenido con la realidad vigente en ambos ordenamientos jurídicos justifica

\footnotetext{
${ }^{1}$ FernÁNDEZ, Luis; Vicent, Francisco, "Internet y el Derecho de sociedades. Una primera aproximación", Revista de Derecho Mercantil, 2000, № 237, pp. 915-1002.
} 
la comparación de los mismos, obviando otros de los que no podría darse debida cuenta de la relación entre sistema normativo y la práctica del tráfico por no tener estrecho contacto con ellos, pero no por esta razón menos relevantes.

Así, se analizará de forma conjunta la situación vigente en Derecho español y Derecho chileno. Es nuestro objetivo mostrar la realidad actual y sustantiva del fenómeno que nos ocupa, sus características en ambos sistemas y transmitir el avance que en cada uno de ellos tiene y la voluntad reformista que pueda existir.

Advertimos que este fenómeno de digitalización de sociedades se encuentra plenamente vivo, en constante evolución y cambio. ${ }^{2}$

Las nuevas tecnologías han servido para revisar el funcionamiento orgánico de la sociedad y la posición jurídica del socio. Han sido el origen de un marco regulador complejo, dando lugar a un proceso de renovación abierto y permanente, a un nuevo modelo cultural, de modo que para el ejercicio telemático de los derechos del socio habrá que tener en cuenta no sólo la ley y los estatutos sociales, sino también los instrumentos de autorregulación adoptados por la sociedad (reglamentos de junta y consejo) e incluso el propio anuncio de la convocatoria. ${ }^{3}$

Sería inabarcable en un trabajo de las características del presente alcanzar a todos los extremos relevantes en los que las nuevas tecnologías han marcado la evolución del Derecho de sociedades. Centramos nuestro objetivo en el análisis del anuncio de convocatoria de junta general a través de medios electrónicos, integrado, por su propia naturaleza, dentro del derecho de información del socio.

En Derecho español, trazaremos el hilo conductor partiendo de la indudable importancia práctica que tiene la regulación de convocatoria de

\footnotetext{
${ }^{2}$ En el ámbito europeo, podemos señalar a modo de ejemplo reciente, la Directiva (UE) 2019/1151 sobre la utilización de herramientas y procesos digitales en el ámbito del Derecho de sociedades. Esta Directiva (UE) 2019/1151 establece normas específicas relativas a la constitución de las sociedades de capital, al registro de sucursales y a la presentación de documentos e información por sociedades y sucursales en línea (procedimientos en línea. En particular, los Estados miembros deben proporcionar información específica sobre los procedimientos en línea previstos en la Directiva y los modelos de escrituras de constitución) en los sitios web accesibles a través de la pasarela digital única.

Los esfuerzos de modernización en Derecho chileno son algo más tímidos. Las normas dictadas en el marco de la modernización atiendes más bien a supuestos puntuales que a una revisión global del Derecho de sociedades tendente a la digitalización. Se profundizará en ello más adelante.

${ }^{3}$ Pérez, Valerio, "Reflexión crítica sobre la incidencia de las nuevas tecnologías en el Derecho de sociedades", Conferencia, Colegio Notarial de Madrid, 14 de febrero de 2008.
} 
junta de general. Se continuará con la exposición de la evolución que ha tenido el artículo 173 del Real Decreto Legislativo 1/2010, de 2 de julio, por el que se aprueba el texto refundido de la Ley de Sociedades de Capital (en adelante, TRLSC).

En fase de revisión de este artículo no ha sido posible obviar, si pretendemos atender a la realidad vigente, el contexto de pandemia que el mundo en su conjunto está atravesando. No nos detenemos el análisis de los principales hitos, pero los hacemos constar.

La respuesta del derecho es latente en todos los ámbitos. En cuanto a derecho de sociedades español se refiere, concretamente en el tema que nos ocupa, la Disposición final octava del Real Decreto Ley (en adelante, RDL) 5/2021 modifica la letra a) del apartado 1 del artículo 3 el RDL $34 / 2020$ para establecer que excepcionalmente, durante el año 2021, a las sociedades de capital previstas en el artículo 1 de la Ley de Sociedades de Capital, se les aplicarán una serie de siguientes medidas que afectan a las sociedades anónimas y que permiten la digitalización parcial o completa de sus juntas generales aunque los estatutos no lo hubieran previsto conforme a las dos hipótesis siguientes: a) Juntas telemáticamente mixtas (presenciales y telemáticas) en las que el consejo de administración podrá prever en la convocatoria de la junta general la asistencia por medios telemáticos y el voto a distancia en los términos previstos en los artículos 182, 189 y 521, así como la celebración de la junta en cualquier lugar del territorio nacional; b) Juntas exclusivamente telemáticas porque "además, el órgano de administración podrá acordar en el anuncio de convocatoria la celebración de la junta por vía exclusivamente telemática, esto es, sin asistencia física de los socios o de sus representantes, siempre que se acompañe de garantías razonables para asegurar la identidad del sujeto que ejerce su derecho de voto y se ofrezca la posibilidad de participar en la reunión por todas y cada una de estas vías: (i) asistencia telemática; (ii) representación conferida al Presidente de la Junta por medios de comunicación a distancia y (iii) voto anticipado a través de medios de comunicación a distancia. Los administradores podrán asistir a la reunión, que se considerará celebrada en el domicilio social con independencia de donde se halle el Presidente de la Junta, por audioconferencia o videoconferencia".

Similar estructura se sigue en Derecho chileno. Será expuesta la regulación de la convocatoria de junta general de accionistas y del aviso de citación. Señalemos que en Derecho chileno tan solo existe regulación 
expresa de la institución para las sociedades anónimas, como emblema de sociedad capitalista. ${ }^{4}$ Dicha regulación se encuentra en los artículos 58 y 59 de la Ley 18.046, Ley sobre Sociedades Anónimas (en adelante, LSA), desarrollados en los artículos 101 a 105 del Reglamento de Sociedades Anónimas, contenido en el Decreto $N^{\circ} 702$ de 2012 del Ministerio de Hacienda.

Semejante actitud a la referida del legislador español ante la situación de pandemia ha sido la del legislador chileno. Se ha promulgado con fecha 17 de noviembre de 2020 la normativa que autoriza el uso de medios tecnológicos para la participación a distancia en las sesiones de directorio de sociedades anónimas. La Norma de Carácter General (en adelante, NCG) $\mathrm{N}^{\circ} 450^{5}$ moderniza las disposiciones normativas establecidas el año 2001, mediante la Circular $\mathrm{N}^{\circ} 1.530$, que regularon la forma en que los directores de las sociedades anónimas abiertas podían asistir de manera remota a sesiones de directorio.

Justifica la actuación en tanto señalando que esta normativa adquiere especial importancia frente a las circunstancias que actualmente afectan a gran parte de la población en Chile y que impiden el libre desplazamiento y la celebración de reuniones de manera presencial con normalidad. La NCG $\mathrm{N}^{\circ} 450$ otorga una autorización general a los medios tecnológicos que cumplan con las condiciones que establece la normativa. Esto es, sistemas que permitan la interacción de los directores en tiempo real, de manera simultánea y permanente.

Vista la regulación, planteamos el supuesto concreto que con carácter imperante se tratará en este trabajo: la convocatoria de junta general mediante página web. Se aborda, como principal problema jurídico en ambos ordenamientos la carencia de ajuste del sistema regulatorio societario con la realidad tecnológica vigente, que impide el mejor aprovechamiento de las ventajas que esta conlleva.

Para finalizar se ofrecerán un conjunto de conclusiones alcanzadas

\footnotetext{
${ }^{4}$ En la regulación de la sociedad anónima, la junta tiene carácter de órgano colegial de carácter corporativo, en cuyo seno se forma y manifiesta la voluntad de la sociedad, a través de un proceso de deliberación y voto de los accionistas que la componen. Dista mucho del caso de las sociedades personalistas, donde la voluntad social se exterioriza mediante la intervención directa de sus administradores, que en el derecho chileno la representan en calidad de mandatarios. Vid. JEQUIER, Eduardo, Curso de Derecho Comercial, Thomson Reuters, Santiago, 2016, Tomo II, Vol. 2, $2^{\mathrm{a}}$ edición, p. 316. A mayor abundamiento, remitimos al Tomo II, Volumen 1 de la misma obra.

${ }^{5}$ Norma de Carácter General CMF № 450, de 17 de noviembre de 2020.
} 
tras el estudio y que se espera puedan ser de utilidad a los operadores del tráfico mercantil.

\section{CONVOCATORIA DE JUNTA GENERAL A TRAVÉS DE MEDIOS ELEC- TRÓNICOS}

\section{La importancia de la convocatoria de junta general y regulación vigente en los ordenamientos español y chileno}

Conforme se ha señalado en las líneas previas de introducción de este trabajo la regulación de convocatoria de junta general es un acto societario de suma importancia. Es el acto inicial para la constitución del órgano deliberante, salvo en el caso de junta universal en Derecho español y en el supuesto previsto en el artículo 60 LSA chilena, que tras la modificación llevada a cabo por la Ley 20382 admite la posibilidad de que la junta se convoque a sí misma, sin necesidad de citación ni avisos previos, siempre y cuando concurran a ella la unanimidad de las acciones emitidas con derecho a voto.

Es un acto formal, que exige el cumplimiento riguroso de los requisitos establecidos, puesto que de su adecuación a las normas que la regulan depende la válida constitución de la junta $\mathrm{y}$, por ende, de los acuerdos que se pretendan adoptar. ${ }^{6-7}$ Los requisitos exigidos legalmente tienen carácter

\footnotetext{
${ }^{6}$ En este sentido, Sentencia de la Audiencia Provincial de Zaragoza (Sección 5a), 16 de febrero, núm. 114/2011: “(...) Salvo los supuestos de junta universal, la celebración de junta ha de ir precedida de su convocatoria, en tiempo y forma, según las normas legales y estatutarias. En otro caso, se debe estimar procedente la convocatoria judicial, que ha de entenderse un remedio subsidiario, que persigue subsanar los defectos que impiden la convocatoria de Junta General por el órgano de administración o la falta de actividad de éste (...)".

${ }^{7}$ En Derecho chileno se observan algunos ápices de menor exigencia de cumplimiento, en el sentido, por ejemplo, en el que se expresa el artículo 59 inc. $3^{\circ} \mathrm{LSA}$, al establecer, respecto a la citación por correo a cada accionista y el contenido de la misma que "La omisión de la obligación a que se refiere el inciso anterior no afectará la validez de la citación, pero los directores, liquidadores y gerente de la sociedad infractora responderán de los perjuicios que causaren a los accionistas, no obstante las sanciones administrativas que la Superintendencia pueda aplicarles." Lo señalado no implica que la convocatoria a junta no sea requisito esencial para la validez de la misma. En este sentido se ha pronunciado la CA de Santiago, 3 de julio de 2015, rol no 8596-2014: 3․ “(...) La omisión de las formalidades prescritas en la Ley 18.046 para convocar a junta extraordinaria de accionistas de una sociedad anónima cerrada produce la nulidad absoluta de dicha junta, en atención a que tales formalidades se encuentran establecidas en consideración a la naturaleza de dicho acto y no a la calidad o estado de las personas que lo ejecutan. En consecuencia, es nula la Junta Extraordinaria de
} 
de Derecho necesario. ${ }^{8}$ Además, constituyen requisitos exigibles los que por vía estatutaria se hayan establecido, siendo su cumplimiento igualmente necesario. ${ }^{9-10}$

La razón última de la exigencia de convocatoria de junta general es garantizar que socios y terceros tengan conocimiento de la celebración y de los puntos a tratar en ella.

Expongamos la evolución del artículo que regula la convocatoria de junta general en Derecho español. Hasta diciembre de 2010 se exigía que la junta general fuera convocada mediante anuncio publicado en el Boletín Oficial del Registro Mercantil (en adelante, BORME) y en uno de los diarios de mayor circulación de la provincia en que estuviese situado el domicilio social. El párrafo segundo del artículo permitía, además, que los estatutos de las sociedades de responsabilidad limitada estableciesen, en sustitución del sistema anterior, que la convocatoria se llevase a cabo por cualquier procedimiento de comunicación, individual y escrita, que asegurase la

Accionistas de Pryse S.A. celebrada el 6 de julio de 2011 y, consecuencialmente, todos los acuerdos adoptados en ella y de los actos y contratos que deriven de tales acuerdos"

${ }^{8}$ En este sentido, Sentencia del Tribunal Supremo (Sala de lo Civil, Sección $1^{\mathrm{a}}$ ), 13 de febrero, núm. 95/2006: "Las referidas formalidades las eleva la Ley, con la fuerza que deriva de las normas de ius cogens, a la condición de exigencias inexcusables como garantías básicas de la regular constitución de la junta en cada caso y, por repercusión, como presupuesto de validez de los acuerdos en ella adoptados (sentencia de 9 de diciembre de 1.999).

La naturaleza imperativa de dichas normas y la correlación entre su incumplimiento, la inválida constitución de la junta y la nulidad absoluta de los acuerdos adoptados han sido destacadas por la jurisprudencia para estas y otras sociedades capitalistas (sentencias de 31 de mayo de 1.983, 17 de diciembre de 1.986, 7 de abril de 1.987, 5 de noviembre de 1.987, 18 de diciembre de 1.987, 25 de marzo de 1.988, 26 de enero de 1.993, 15 de noviembre de 1.994 y 14 de marzo de 2.005). (...).

En conclusión, la junta ordinaria no se constituyó válidamente, de modo que, conforme a lo expuesto, los acuerdos que de ella nacieron tampoco son válidos, aunque permitieran formar una mayoría.

La invalidez de esos acuerdos, por razón del vicio de la reunión que los generó, es la propia de la nulidad absoluta y aunque nada dice la Ley sobre la legitimación para impugnar acuerdos nulos por defectos en la constitución de la junta, no hay razón para limitarla con la exigencia de requisitos que vienen establecidos sólo para los acuerdos anulables (artículo 117.2 del texto refundido de la Ley de Sociedades Anónimas, en relación con el 56 de la Ley 2/1.995) (...)”.

${ }^{9}$ Pérez, Aránzazu, "De nuevo sobre la convocatoria de junta general de sociedades de capital tras la reciente reforma del artículo 173 de la Ley de Sociedades de Capital", Diario La Ley, 2012, № 7914.

${ }^{10} \mathrm{~A}$ los efectos que en este trabajo nos interesan, resulta imprescindible señalar el contenido del artículo 8 , inc. $2^{\circ}$ del Reglamento, cuando señala que "los estatutos de la sociedad podrán establecer medios de comunicación de la sociedad a los accionistas complementarios a los indicados en la ley o en este reglamento. En este caso, el Registro de Accionistas deberá incluir respecto de cada accionista, además, la información necesaria para utilizar aquellos medios de comunicación.

Será responsabilidad de cada accionista mantener su información en el Registro de Accionistas debidamente actualizada". 
recepción del anuncio por todos los socios en el domicilio designado al efecto o en el que conste en el libro-registro de socios.

Con la reforma llevada a cabo mediante el Real Decreto-ley 13/2010, de 3 de diciembre, de actuaciones en el ámbito fiscal, laboral y liberalizadoras para fomentar la inversión y la creación de empleo, la junta general de las sociedades de capital debía convocarse mediante anuncio publicado en BORME y en la página web de la sociedad si existía, y en caso de no existir, en uno de los diarios de mayor circulación en la provincia en que estuviera situado el domicilio social. De igual modo que en la versión anterior del artículo, se permitía a las sociedades de responsabilidad limitada establecer por vía estatutaria que la convocatoria se llevase a cabo por cualquier procedimiento de comunicación, individual y escrita, que asegurase la recepción del anuncio por todos los socios en el domicilio designado al efecto o en el que conste en el libro-registro de socios.

Las divergentes interpretaciones prácticas que conllevó la aplicación de esta norma requirieron de la intervención de la Dirección General de los Registros y del Notariado (en adelante, DGRN), mediante Instrucción de fecha 18 de mayo de 2011. ${ }^{11}$ Aclaraba que en los casos en los que se optara por la publicación de la convocatoria de la junta general en la página web, la sociedad debería o bien determinar la página web en los estatutos de la sociedad o bien notificar a todos los socios la existencia y dirección electrónica de dicha página web y el sistema de acceso a la misma. El anuncio de convocatoria deberá estar publicado en la página web de la sociedad desde la fecha de aquella hasta la efectiva celebración de la junta general. El contenido de la convocatoria se ajustaría a lo dispuesto en el artículo 174 TRLSC.

No habría transcurrido un año cuando se vuelve a modificar el artículo que nos ocupa. Se haría mediante la Ley 25/2011, de 1 de agosto, de reforma parcial de la Ley de Sociedades de Capital y de incorporación de la Directiva 2007/36/CE, del Parlamento Europeo y del Consejo, de 11 de julio, sobre el ejercicio de determinados derechos de los accionistas de sociedades cotizadas. La nueva redacción del artículo obligaba a la convocatoria de junta general mediante anuncio publicado en la página web de la sociedad. Para el supuesto de que no la tuviese o con carácter voluntario y adicional, la convocatoria se publicaría en uno de los diarios de mayor circulación

${ }^{11}$ Boletín Oficial del Estado (en adelante, BOE) de 25 de mayo de 2011. 
de la provincia en que estuviera situado el domicilio social. Se permitiría, además, el establecimiento de la convocatoria por vía estatutaria a través cualquier procedimiento de comunicación, individual y escrita, que asegure la recepción del mismo por todos los socios en el domicilio designado al efecto o en el que constare en la documentación de la sociedad. Las únicas sociedades que no podrían acogerse a este sistema sustitutorio serían las sociedades anónimas con acciones al portador, en las que la convocatoria debía realizarse, al menos, mediante anuncio publicado en el BORME.

La redacción actual del artículo viene dada por la Ley 1/2012, de 22 de junio, de simplificación de las obligaciones de información y documentación de fusiones y escisiones de sociedades de capital. De la lectura del actual artículo 173.1 TRLSC se infiere claramente que, en principio, la junta general debe ser convocada mediante anuncio publicado en la web de la sociedad, siempre que dicha página haya sido creada, inscrita y publicada conforme a lo dispuesto en el artículo 11 bis TRLSC.

En su párrafo segundo se autoriza a que, en sustitución de la forma de convocatoria prevista en el artículo 173.1 TRLSC, se establezca por vía estatutaria que la convocatoria se lleve a cabo por cualquier otro procedimiento de comunicación individual y escrita, que debe asegurar la recepción del anuncio por todos los socios en el domicilio designado al efecto o en el que conste en la documentación de la sociedad. Además, para el supuesto particular de socios residentes en el extranjero, los estatutos pueden prever que únicamente serán individualmente convocados si hubieran designado un lugar del territorio nacional para notificaciones.

Por último, el vigente artículo 173 TRLSC finaliza autorizando a que, por vía estatutaria, se establezcan mecanismos adicionales de publicidad a los previstos en la ley y se imponga a la sociedad la gestión telemática de un sistema de alerta a los socios de los anuncios de convocatoria insertados en la web de la sociedad.

Vista la regulación en Derecho español, expongamos la propia en Derecho chileno. Autores nacionales han venido a denominar a los formalismos propios de la convocatoria y la citación "los procedimientos previos a la reunión de las juntas de accionistas". ${ }^{12}$

El directorio de la sociedad es el encargado de practicar las respectivas citaciones a la junta, en los casos señalados por el artículo 58 LSA: 1) A

${ }^{12}$ Olavarría, Julio, Manual de Derecho Comercial, Clarase, Barcelona, 1970, $3^{\text {a }}$ edición, p. 390. 
junta ordinaria, a efectuarse dentro del cuatrimestre siguiente a la fecha del balance, con el fin de conocer de todos los asuntos de su competencia; 2) A junta extraordinaria siempre que, a su juicio, los intereses de la sociedad lo justifique; 3) A junta ordinaria o extraordinaria, según sea el caso, cuando así lo soliciten accionistas que representen, a lo menos, el 10\% de las acciones emitidas con derecho a voto, expresando en la solicitud los asuntos a tratar en la junta; 4) A junta ordinaria o extraordinaria, según sea el caso, cuando así lo requiera la Superintendencia, ${ }^{13}$ con respecto a las sociedades anónimas abiertas o especiales, sin perjuicio de su facultad para convocarlas directamente. En el caso de las sociedades anónimas cerradas, si el directorio no ha convocado a junta cuando corresponde, accionistas que representen, a lo menos, el 10\% de las acciones emitidas con derecho a voto, podrán efectuar la citación a junta ordinaria o extraordinaria, según sea el caso, mediante la publicación de un aviso en un diario de circulación nacional, en el cual expresarán la fecha y hora en que se llevará a cabo y los asuntos a tratar en la junta. ${ }^{14}$

Conforme a lo establecido en el artículo 59 LSA, tratándose de la primera citación a junta, ésta debe hacerse por medio de un aviso destacado que se publicará, a lo menos, por tres veces en días distintos en el periódico del domicilio social que hay determinado la junta de accionista. Debe contener indicación acerca de: la naturaleza de la junta; el lugar, fecha y hora de la celebración y en el caso de junta extraordinaria, las materias a tratar en ella (conforme a lo dispuesto en artículo 104 del Reglamento). En caso de suspensión o desaparición de la circulación del periódico designado, en el Diario Oficial, en el tiempo, forma y condiciones que señale el Reglamento.

En segunda citación los avisos sólo podrán publicarse una vez que hubiese fracasado la junta prevista para primera citación. Deben cumplir igualmente con los requisitos indicados anteriormente.

Hasta aquí el tenor literal de parte los artículos, donde no hemos mencionado referencia alguna a la posibilidad de convocatoria de junta

\footnotetext{
${ }^{13}$ Téngase en cuenta que en virtud de la Ley $N^{\circ} 21.000$ del Ministerio de Hacienda de 23 de febrero de 2017, se crea la Comisión para el Mercado Financiero (en adelante, CMF) y reemplaza el texto del decreto ley $\mathrm{N}^{\circ} 3.538$, de 9 de diciembre de 1980, publicado en el Diario Oficial $\mathrm{N}^{\circ} 30.847$ de 23 de diciembre de 1980, que crea la Superintendencia de Valores y Seguros.

${ }^{14}$ La última parte de este inciso se incluye, por la Ley 20.382, con intención de solucionar la situación de una sociedad anónima cerrada en la que el directorio, por haber entrado en pugna con algún grupo de accionistas, impide que se pueda exigir la citación a la junta. Así queda expuesto en el Segundo informe de la Comisión de Hacienda, que se aporta en la propia Historia de la Ley.
} 
por medios electrónicos. Añadimos ahora algunas precisiones respecto a la normativa considerada. Por resultar clara y concisa seguimos la exposición del profesor SANDOVAL. ${ }^{15}$

Una precisión inicial respecto al aspecto objetivo en esta materia. Cuando se trata de sociedades anónimas abiertas ${ }^{16}$ existe la obligación de los dirigentes sociales de comunicar a la Comisión para el Mercado Financiero (CMF), con antelación no inferior a quince días, la fecha de la reunión de las juntas generales de accionistas en cuyo seno el servicio público encargado de su fiscalización puede hacerse representar, así queda establecido en el artículo 63 LSA. La CMF tiene facultad de suspender por resolución fundada la citación a la junta de accionistas y la propia junta, cuando sea contraria a la ley, reglamento o los estatutos.

Señalamos ahora, dentro del procedimiento previo a la celebración de la junta general, algunos aspectos relativos a la comunicación de documentos sociales en los que se favorece, por la propia norma, el empleo de nuevas tecnologías.

Atendamos a la comunicación de los documentos sociales, que se integra (al igual que la obligación de convocatoria) en el marco del deber (para la sociedad)/derecho (para el accionista) de información. El articulo 54 LSA establece que la memoria, balance, inventario, actas, libros y los informes de los auditores externos y, en su caso, de los inspectores de cuentas, quedarán a disposición de los accionistas para su examen en la oficina de la administración de la sociedad, durante los quince días anteriores a la fecha señalada para la junta de accionistas. Los accionistas sólo podrán examinar dichos documentos en el término señalado. Existe, conforme a lo dispuesto en el mismo artículo, la posibilidad de reserva de dichos documentos para el caso en que se refieran a negociaciones aún pendientes que al conocerse

\footnotetext{
${ }^{15}$ Sandoval, Ricardo, Derecho comercial. Tomo I, Editorial Jurídica de Chile, Santiago, 2015, pp. 578-584.

${ }^{16}$ Reproducimos parte del contenido del artículo 2 LSA: "Las sociedades anónimas pueden ser de tres clases: abiertas, especiales o cerradas.

Son sociedades anónimas abiertas aquellas que inscriban voluntariamente o por obligación legal sus acciones en el Registro de Valores; son sociedades anónimas especiales las indicadas en el Título XIII de esta ley; son sociedades anónimas cerradas las que no califican como abiertas o especiales.

Las sociedades anónimas abiertas y las sociedades anónimas especiales quedarán sometidas a la fiscalización de la Superintendencia de Valores y Seguros, en adelante la Superintendencia, salvo que la ley las someta al control de otra Superintendencia. En este último caso, quedarán además sometidas a la primera, en lo que corresponda, cuando emitieren valores".
} 
pudieran perjudicar el interés social.

En este mismo artículo encontramos la primera referencia al empleo de medios electrónicos en sede de convocatoria de junta general. Establece, en su último párrafo, que, en el caso de las sociedades anónimas abiertas, la memoria, el informe de los auditores externos y los estados financieros auditados de la sociedad, deberán ponerse a disposición de los accionistas en el sitio en Internet de las sociedades que dispongan de tales medios. ${ }^{17}$

En cuanto al envío de documentos sociales a los accionistas, en las sociedades anónimas abiertas, en una fecha no posterior a la del primer aviso de convocatoria para la junta ordinaria, el directorio debe poner a disposición de cada uno de los accionistas inscritos en registro, una copia del balance y de la memoria de la sociedad, incluyendo el dictamen de los auditores y sus notas respectivas. En este punto relativo a publicidad de documentos, vuelve a aparecer la electronificación del Derecho de sociedades. Establece el artículo 76 LSA que las sociedades anónimas abiertas deberán publicar en su sitio en Internet, con la disponibilidad y por el plazo que determine la CMF, la información sobre sus estados financieros y el informe de los auditores externos, con no menos de diez días de anticipación a la fecha en que se celebre la junta que se pronunciará sobre los mismos. Esta información y el hipervínculo al sitio de Internet de la sociedad donde dicha información se ubique, deberá presentarse dentro de ese mismo plazo a la CMF, para que así ésta pueda publicarlo en su sitio de Internet, facilitando de esta forma el acceso por parte del público a la información, debiendo la sociedad informar conjuntamente la fecha de publicación de tales antecedentes en su sitio en Internet.

Si la sociedad no cuenta con un sitio en Internet para efectuar las publicaciones referidas en los incisos anteriores, deberá realizarlas en un diario de amplia circulación, en el lugar del domicilio social, con no menos de diez ni más de veinte días de anticipación a la fecha en que se celebre la junta que se pronunciará sobre los estados financieros y el informe de los auditores externos.

En las sociedades anónimas cerradas se enviará la memoria y el balance a los accionistas que lo soliciten.

${ }^{17}$ Este párrafo fue introducido por la Ley 20.382, que introduce perfeccionamientos a la normativa que regula los gobiernos corporativos de las empresas. 
2. Análisis de caso concreto de convocatoria de junta general a través de la página web en Derecho español y Derecho chileno.

Concretemos en los siguientes párrafos la posibilidad de convocatoria de junta general, tanto en Derecho español como en Derecho chileno, a través de la página web.

\subsection{Situación del Derecho español}

En Derecho español, esta cuestión exige describir el concepto de página web corporativa atendiendo a la legislación vigente y señalar las diferencias entre sociedades cotizadas y no cotizadas a nivel tanto jurídico como fáctico. Expondremos datos estadísticos que permitan conocer el alcance real del fenómeno y concretaremos los requisitos relativos a acreditación y mantenimiento de convocatoria a los que se debe dar cumplimiento. En Derecho chileno se atiende a una estructura muy similar, debiendo ser consciente el lector del menor desarrollo legislativo y reglamentario del fenómeno, lo hace que las posibilidades de concreción sean más limitadas.

Comencemos con unas indicaciones generales acerca del concepto de web corporativa, su creación y requisitos técnicos.

Dispone el artículo 11 bis.1 TRLSC que las sociedades de capital podrán disponer de página web corporativa, estableciéndolo como obligación para las sociedades cotizadas. Incidamos la referencia que se hace a página web corporativa. Es decir, no nos encontramos ante un precepto referido a cualquier página web que pudiera ser comercial o destinada a efectos meramente publicitarios.

La página web corporativa de una sociedad de capital es, obviamente, una página web, pero que tiene dos particularidades: que ha sido creada como tal, con todos los efectos legales que ello supone, y que cumple los requisitos técnicos que establece la legislación para que una página web pueda ser considerada corporativa. En cuanto a la creación, el artículo 11 bis TRLSC dispone los requisitos exigibles. ${ }^{18}$ En sentido técnico, las exigencias

\footnotetext{
18 “2. La creación de una página web corporativa deberá acordarse por la junta general de la sociedad. En la convocatoria de la junta, la creación de la página web deberá figurar expresamente en el orden del día de la reunión. Salvo disposición estatutaria en contrario, la modificación, el traslado o la supresión de la página web de la sociedad será competencia del órgano de administración.

3. El acuerdo de creación de la página web se hará constar en la hoja abierta a la sociedad en el Registro
} 
se recogen en el artículo 11 ter TRLSC. ${ }^{19}$

Nada obsta que la sociedad pueda mantener otras páginas web no corporativas, siendo frecuente la inclusión de la página web corporativa en otras, especialmente en sociedades cotizadas y pudiendo utilizarse la página web corporativa para otros fines siempre que se ajuste al régimen legal. Lo que es indudable es que la utilización para la convocatoria de junta general de otra web que no fuese corporativa carecería de efectos jurídicos. ${ }^{20}$

La publicidad de la información en la web corporativa surtirá efectos una vez que se hayan cumplido las exigencias formales de inscripción en el Registro Mercantil y publicada en BORME, se haya notificado individualmente a los socios si así se exige estatutariamente y cumpla las exigencias técnicas referidas.

Prosigamos señalando las especialidades que encontramos para sociedades cotizadas. La sociedad cotizada fue el ámbito inicial de utilización de la página web corporativa, que posteriormente devendría en obligación.

Mercantil competente y será publicado en el "Boletín Oficial del Registro Mercantil".

El acuerdo de modificación, de traslado o de supresión de la página web se hará constar en la hoja abierta a la sociedad en el Registro Mercantil competente y será publicado en el "Boletín Oficial del Registro Mercantil", así como en la propia página web que se ha acordado modificar, trasladar o suprimir durante los treinta días siguientes a contar desde la inserción del acuerdo.

La publicación de la página web de la sociedad en el "Boletín Oficial del Registro Mercantil" será gratuita. Hasta que la publicación de la página web en el "Boletín Oficial del Registro Mercantil" tenga lugar, las inserciones que realice la sociedad en la página web no tendrán efectos jurídicos.

Los estatutos sociales podrán exigir que, antes de que se hagan constar en la hoja abierta a la sociedad en el Registro Mercantil, estos acuerdos se notifiquen individualmente a cada uno de los socios."

19 "1. La sociedad garantizará la seguridad de la página web, la autenticidad de los documentos publicados en esa página, así como el acceso gratuito a la misma con posibilidad de descarga e impresión de lo insertado en ella.

2. La carga de la prueba del hecho de la inserción de documentos en la página web y de la fecha en que esa inserción haya tenido lugar corresponderá a la sociedad.

3. Los administradores tienen el deber de mantener lo insertado en la página web durante el término exigido por la ley, y responderán solidariamente entre sí y con la sociedad frente a los socios, acreedores, trabajadores y terceros de los perjuicios causados por la interrupción temporal de acceso a esa página, salvo que la interrupción se deba a caso fortuito o de fuerza mayor. Para acreditar el mantenimiento de lo insertado durante el término exigido por la ley será suficiente la declaración de los administradores, que podrá ser desvirtuada por cualquier interesado mediante cualquier prueba admisible en Derecho.

4. Si la interrupción de acceso a la página web fuera superior a dos días consecutivos o cuatro alternos, no podrá celebrarse la junta general que hubiera sido convocada para acordar sobre el asunto a que se refiera el documento inserto en esa página, salvo que el total de días de publicación efectiva fuera igual o superior al término exigido por la ley. En los casos en los que la ley exija el mantenimiento de la inserción después de celebrada la junta general, si se produjera interrupción, deberá prolongarse la inserción por un número de días igual al que el acceso hubiera estado interrumpido."

${ }^{20}$ En este sentido, Resolución DGRN del 2 de noviembre de 2016. BOE de 23 de noviembre de 2016. 
Esta obligación encuentra su origen en el Informe Aldama, en un intento de promover la participación del socio en junta general. ${ }^{21}$

Específicamente, en la regulación de sociedades cotizadas el TRLSC recoge el uso de la página web para la publicación de convocatoria de junta general. Establece un contenido mínimo exigible: la dirección de la página web de la sociedad en la que estará disponible la información, ${ }^{22}$ información general previa a la celebración de la junta ${ }^{23}$ y otras relativas al ejercicio del derecho de información por el socio, acuerdos adoptados e indicaciones de índole económica.

Frente a la situación que observamos en sociedades cotizadas donde la obligatoriedad de existencia de página web es razón de su amplia utilización, en el panorama actual de sociedades no cotizadas encontramos notables diferencias. Son ilustrativas las estadísticas mercantiles publicadas por el Colegio de Registradores que recogen el número de inscripciones de páginas web. Hasta la fecha indicada de consulta, en 2019 se han inscrito un total de 32 páginas web corporativas, 4 de sociedades anónimas (en adelante, SA) y 2 de otros tipos societarios. ${ }^{24}$ En relación con el número de sociedades existentes y de nueva constitución la cifra es irrisoria. ${ }^{25}$ Nos sorprende el escaso número de sociedades de capital que en los últimos años optan, en ejercicio del derecho que les confiere la ley, por la creación y utilización de la página web corporativa. Desconociendo las razones organizativas y económicas que puedan fundamentar estos datos, jurídicamente, podría encontrarse razón en la incertidumbre e inseguridad jurídica que las numerosas modificaciones legislativas de un mismo precepto suelen conllevar.

Sea cual fuere la razón que aleja a las sociedades de capital de la

\footnotetext{
${ }^{21}$ Comisión Especial para el Fomento de la Transparencia y la Seguridad en los Mercados Financieros y las Sociedades Cotizadas (Eds.), "Informe de la Comisión Especial para el Fomento de la Transparencia y la Seguridad en los Mercados Financieros y las Sociedades Cotizadas (Informe Aldama)", Gobierno de España, Madrid, 2003, IV. 1.

${ }^{22}$ Artículo 517 TRLSC.

${ }^{23}$ Artículo 518 TRLSC.

${ }^{24}$ Colegio de Registradores de España (Eds.), "Páginas web corporativas inscritas. Informe de estadística mercantil", 2019, documento .html disponible en línea: https://www.registradores.org/ estaticasm/Estadistica/2019/septiembre/paginas/dominios_inscritos.htm (Consultada: 7 de noviembre 2019).

${ }^{25}$ Colegio de Registradores de España (Eds.), "Constituciones de sociedades. Informe de estadística mercantil", 2019, documento .html disponible en línea: https://www.registradores.org/estaticasm/ Estadistica/2019/septiembre/paginas/constituciones.htm (Consultada: 7 de noviembre 2019).
} 
creación de la página web corporativa, la consecuencia necesaria de ello es encontrar a la mayoría de las sociedades de capital convocando juntas generales sirviéndose de los tradicionales procedimientos.

Como última cuestión a señalar en Derecho español dentro de este epígrafe, atendemos a la acreditación y mantenimiento de la convocatoria en página web.

El régimen legal de las publicaciones insertas en la página web corporativa queda definido, como se ha señalado previamente, en el artículo 11 ter TRLSC. Puede valorarse como un régimen peculiar, además de impreciso.

El legislador impone a la sociedad la obligación de cumplir con una serie de garantías mínimas de acceso a las publicaciones en la web, que serían de aplicación al documento que contiene la convocatoria de junta general.

En términos generales de seguridad se exige la garantía de que las informaciones no han sido modificadas indebidamente, es decir, integridad de contenido.

Se requiere la autenticidad de los documentos publicados. Dentro de esta exigencia podríamos identificar una doble vertiente. Por un lado, implica que el documento que se publica (en el caso que nos ocupa la convocatoria de junta general) proviene de la persona que legalmente está habilitada para hacerlo; y por otro lleva consigo, también, que ese documento que se publica es precisamente el que esa persona pretende publicar.

En cualquier convocatoria de junta es un punto esencial para su validez que se indique la persona o personas que la realizan y los cargos que ostentan en la sociedad y que les habilitan para ello. ${ }^{26}$

Esto supone que la inserción de una convocatoria en la web corporativa sólo la pueden realizar o bien el administrador único, o cualquiera de los administradores solidarios, los administradores mancomunados actuando conjuntamente todos ellos o el Consejo de administración adoptando un acuerdo que se plasman una certificación firmada por el secretario con el visto bueno del presidente.

Con los sistemas de firma electrónica actuales, como con los procesos correspondientes de identificación de personas y de los cargos 
correspondientes en la sociedad, es posible llevar a cabo este control, dado que permiten hacer un seguimiento y un almacenamiento informático que garanticen la titularidad y autoría del acto de la publicación y del contenido de la publicación en sí mismo. ${ }^{27}$

Además, debe garantizarse por la sociedad el acceso gratuito, descarga e impresión del documento.

Con la regulación vigente recae sobre la sociedad la prueba de la inserción y de la fecha en que se realiza.

Podrá cumplir con esta carga mediante cualquier medio de prueba admitido en Derecho. Se estimaría válida, por tanto, la impresión de la citada página web el día en que se haya incorporado el anuncio (figurando en la parte inferior tanto la URL como la fecha de la impresión).

Siendo más efectivo, aunque también más costoso, la sociedad podrá recurrir a la incorporación a un acta notarial y, posteriormente, se testimoniará en la escritura de elevación a público de acuerdos sociales o en el acta de presencia en junta general conforme a lo dispuesto en los artículos $101 \mathrm{y}$ 107.2 del Real Decreto 1784/1996, de 19 de julio, por el que se aprueba el Reglamento del Registro Mercantil (en adelante, RRM). ${ }^{28}$

Constituirían otras formas de prueba el acceso a través de sistemas propios al servidor donde se aloje la web corporativa, la intervención de terceros de confianza y el empleo de sistemas de certificación mediante sellado o marca de tiempo, conocido como timestamping.

La reforma del año 2012 establecía una obligación legal de mantenimiento ininterrumpido de la información insertada en la web durante los plazos previstos para cada caso por la ley. En el supuesto que nos ocupa los plazos establecidos en el artículo 176 como plazos previos de convocatoria de junta general. En términos de prueba se establece una presunción legal iuris tantum, siendo suficiente la declaración de los administradores que podrá ser desvirtuada por cualquier interesado mediante cualquier medio de prueba admisible en Derecho. Esta disposición supone un ahorro de costes para la sociedad, pero sitúa al socio ante una probatio diabólica.

El apartado cuarto del artículo al que nos venimos refiriendo concreta

\footnotetext{
${ }^{27}$ JORQUERA, Lis, "La web corporativa como instrumento de relación de las sociedades mercantiles con socios y terceros. Aspectos prácticos", Diario La Ley, 2013, No 8186.

${ }^{28}$ Nieto, Ubaldo, "Convocatoria de junta general a través de la web social", Actualidad Jurídica Aranzadi, 2012, № 836, p. 5.
} 
los efectos que sobre la celebración junta general convocada a través de página web corporativa tendría la interrupción temporal del acceso. Sistematizando el contenido del precepto podría concluirse que si la junta general se ha convocado para acordar un asunto al que se refiera el documento inserto en la página web corporativa y la interrupción supera los dos días consecutivos o cuatro alternos ${ }^{29}$ no podrá celebrarse la junta general. Se establece excepción a la prohibición de celebrarse junta general para el caso de que la publicación efectiva fuera igual o superior al plazo legalmente establecido.

\subsection{Situación del Derecho chileno}

Prosigamos con la concreción del fenómeno en Derecho chileno. El legislador chileno, cuando decide incluir unas notas de electronificación del Derecho de sociedades a través de la ya mencionada Ley 20.382 no define el concepto que en ella emplea de "sitio de internet".

En respuesta a esta laguna conceptual, la anterior Superintendencia (actual CMF) en fecha el 15 de abril de 2010 publica el oficio circular número 599. Haciendo uso de sus facultades legales establece que se entenderá que una sociedad anónima abierta dispone de un sitio de Internet, cuando ésta o las sociedades del grupo empresarial a que aquella pertenece, mantienen a disposición del público, directamente o a través de un tercero, un sitio de Internet destinado a entregar información respecto de esa sociedad anónima. Señala, además la información que la sociedad deberá mantener a disposición del público en su sitio de Internet, conforme a lo prescrito en la LSA. ${ }^{30}$ Adviértase que el oficio se dirige expresamente a "sociedades

${ }^{29}$ Las interrupciones inferiores tan solo conllevan exigencia de responsabilidad.

${ }^{30}$ La información que la sociedad deberá mantener a disposición del público en su sitio de Internet, conforme a lo prescrito en la Ley $\mathrm{N}^{\circ} 18.046$, en relación con las disposiciones que se indican en cada caso, será la siguiente (en negrita las relacionadas con el tema que nos ocupa):

a) Estatutos actualizados, conforme a lo requerido en el inciso primero del artículo $7^{\circ}$.

b) Las disminuciones de capital, conforme a lo establecido en el inciso segundo del artículo 28.

c) Estados financieros de la sociedad, informe de las empresas de auditoría externa y la memoria, conforme a lo requerido en el inciso cuarto del artículo 54 y en inciso segundo del artículo 76, en lo que corresponda.

d) Los documentos que fundamentan las diversas opciones que serán sometidas a voto, de acuerdo a lo dispuesto en el inciso segundo del artículo 59.

e) Aviso que comunica el derecho a retiro a favor de los accionistas debido a que el accionista controlador alcanzó la participación del 95\% de las acciones de la sociedad anónima, de acuerdo a lo establecido en el 
anónimas abiertas".

Añade que en aquellos casos en que la ley no señale un plazo específico para la publicación de la información en los sitios de Internet, la sociedad estará obligada a divulgarla tan pronto como los medios tecnológicos de que disponga, se lo permitan.

Todo lo anterior es sin perjuicio del cumplimiento de las demás disposiciones y normas referidas a divulgación de información vía Internet o aquellas que la propia sociedad se comprometa a mantener en sus sitios de Internet.

En el último "Informe Final Fortalecimiento de Estándares de Gobierno Corporativo de las Sociedades Anónimas Abiertas", al que hemos podido tener acceso, encontramos que ante la pregunta de si la sociedad cuenta con una página web actualizada por medio de la cual los accionistas pueden acceder a toda su información pública, de manera sencilla y de fácil acceso. Esta recomendación es adoptada por cerca del 90\% de las sociedades en ambos periodos, el resto en su mayoría no indicó las razones del no cumplimiento. Una sociedad que sí proporcionó una explicación señalo: "No, lamentablemente aún no tenemos página web, pero actualmente estamos buscando resolver esta carencia". ${ }^{31}$ La conciencia de las sociedades hacia la inclusión de medios tecnológicos en el sentido de tenencia de páginas web resulta muy positiva en el contexto societario chileno. Ahora bien, en otros aspectos como la votación remota o la divulgación en tiempo real de juntas no ha gozado de éxito, que pudiera estar vinculada a la desconfianza de los accionistas de depender de los medios web para el ejercicio de sus derechos, unido a la ausencia de una política de incentivos para su implementación.

Hasta aquí la definición del concepto de sitio de internet y la

inciso primero del artículo 71 bis a.

f) La notificación del ejercicio del derecho de compra del controlador, conforme a lo establecido en el inciso tercero del artículo 71 bis.

g) Actas de la última junta ordinaria de accionistas y de la última junta extraordinaria de accionistas, de acuerdo a lo señalado en el inciso final del artículo 72.

h) Informes de los evaluadores independientes a que se refiere el párrafo segundo del numeral 5) del inciso primero del artículo 147.

i) Las opiniones de los directores, a que se refiere el numeral 6) del inciso primero del artículo 147.

j) El acuerdo que establece las políticas de habitualidad y sus modificaciones, de conformidad a lo establecido en la letra b) del inciso segundo del artículo 147.

${ }^{31}$ Superintendencia de Valores y Seguros, "Informe Final Fortalecimiento de Estándares de Gobierno Corporativo de las Sociedades Anónimas Abiertas", 2014. Disponible en: http://www.cmfchile.cl/portal/ principal/605/articles-20924_doc_pdf.pdf(Consultada: 7 de noviembre 2019). 
consideración de datos reales de la existencia del mismo.

Incluimos un último aspecto, que en nuestra opinión es el que toma importancia capital con la regulación actual de la materia que nos ocupa en Chile. Nos referimos al ya mencionado artículo 8 del Reglamento. Conforme a su tenor literal, cuando la sociedad deba citar a los accionistas, realizar algún anuncio o entregar información relevante a éstos, lo deberá realizar en la forma establecida en la ley, y en ausencia de norma, mediante comunicación escrita entregada personalmente a cada accionista o por carta certificada enviada al domicilio informado en el Registro de Accionistas.

Además, dicha citación o información, deberá estar disponible en el sitio de internet de la sociedad, si lo tuviera. Establece también que los estatutos de la sociedad podrán establecer medios de comunicación de la sociedad a los accionistas complementarios a los indicados en la ley o en este reglamento.

A pesar de centrar nuestro estudio en la convocatoria a través de página web, por ser el medio elegido para su comparación con Derecho español, señalamos algunos aspectos relativos a la posibilidad de convocatoria mediante correo electrónico y diarios electrónicos. Entendemos enriquecen la aportación.

Así, conforme a lo dispuesto en Oficio $N^{\circ} 13172$ de 01/04/2020, de la Comisión para el Mercado Financiero sería factible notificar una citación a junta de accionistas por correo electrónico de manera adicional a la citación indicada en el primer inciso del art.59 de la LSA. Sin perjuicio de lo anterior, en forma complementaria, los estatutos podrán incorporar otros medios de comunicación distintos a los indicados en la LSA o en el RSA. Por otro lado, el poner a disposición de los accionistas un determinado formato de poder, no restringe la presentación de un formato distinto, siempre que cumpla con el contenido que indica el RSA. La sociedad debe poner a disposición la citación y cualquier otro anuncio o información relevante en la página web de la sociedad. Nada impide que el envío-recepción y presentación de dicho poder, pueda realizarse a través del uso de medios digitales y dispositivos tecnológicos, tales como Internet, ya sea adjuntando el correspondiente archivo electrónico en donde conste copia digitalizada del poder conferido.

Los diarios electrónicos se consideran, para los efectos de la publicación de que se trata, como periódicos de circulación nacional. Así queda establecido en textos normativos como Circular Cooperativas $\mathrm{N}^{\circ}$ 140 de 26 de enero de 2010 o en el Compendio de Normas del Sistema de 
Pensiones. Se ha comprobado que se ve materializado en la realidad del tráfico. ${ }^{32}$

El legislador chileno se ha mostrado favorable al empleo de las nuevas tecnologías y al respeto al principio de la autonomía de la voluntad en la regulación societaria. Insta a la comunicación a través del sitio de Internet de la sociedad y, además, permite que en los estatutos se puedan establecer medios de comunicación complementarios, entre los que cabría la propia página web de la sociedad o incluso el correo electrónico.

La regulación chilena puede entenderse, conforme hemos comentado, favorable a la convocatoria de junta general mediante página web, pero muy escasamente desarrollada a nivel normativo y con un considerable carácter fragmentario. Esto puede infundir inseguridad jurídica a los operadores del tráfico. A continuación, valoraremos diversos aspectos susceptibles de mejora que esperamos puedan ser de utilidad.

\section{REFLEXIONES, CONCLUSIONES Y RETOS}

Tras el acercamiento que un trabajo de estas características nos permite al empleo de medios de comunicación electrónicos en sociedades de capital para llevar a cabo la convocatoria de junta general, podemos concluir que una rápida ponderación de argumentos a favor y en contra de su utilización inclinarían la balanza a favor de estos.

Manifestamos nuestro sentir crítico y de sorpresa ante la situación de hecho en el caso español, donde la mayoría de las sociedades de capital continúan haciendo uso de mecanismos tradicionales para la publicación del anuncio de convocatoria. Bien es cierto que la publicación a través de web corporativa (la única prevista expresamente en la ley y a su vez la menos utilizada), requiere de su creación, inscripción y publicación por parte de la sociedad. Pero los costes que estos trámites conllevan, tanto en sentido económico como jurídico quedarían compensados con las ventajas que proporciona su tenencia. Desde una vertiente jurídica, la creación de la página web no se presenta como un procedimiento complejo.

${ }^{32}$ A modo de ejemplo, véase la citación a junta extraordinaria de accionistas de SOPROLE Inversiones S.A.: https://www.extranoticias.cl/avisos-legales/citacion-a-junta-extraordinaria-de-accionistassoprole-05-02-2021/. 
El análisis reflexivo aplicado al Derecho societario chileno nos lleva a manifestar preocupación por la escasa regulación del fenómeno. Efectivamente, el legislador ha dado algunos pasos en pos de la renovación de la legislación societaria, si bien se trata de esfuerzos tímidos que no alcanzan a una revisión profunda de la institución societaria, sino a soluciones concretas que se otorgan frente a circunstancias puntuales. El sistema en su conjunto se caracteriza por normas disgregadas en diferentes cuerpos legales, sin ordenación coherente con notorios vacíos normativos. ${ }^{33}$ Las normas existentes, en su mayor parte, hacen referencia a una posibilidad (exclusiva) para las sociedades anónimas abiertas, consistente en hacer uso de los sitios de Internet "si se dispone de ellos". Abrimos la pregunta acerca de si podría ser más conveniente, en una etapa de digitalización como la que vivimos, impulsar el uso estableciendo el carácter obligatorio en concretos supuestos, como se ha hecho con la sociedad cotizada en Derecho español.

La profesora VÁsQuEZ entiende (y nosotros lo compartimos) que es preciso, de lege ferenda, efectuar una reforma al marco societario chileno en su conjunto de manera consciente y decidida, entendiendo que modernizar no equivale a modificar sino en avanzar hacia las fronteras del conocimiento. ${ }^{34}$ Advertimos también, al igual que hacen otros autores, ${ }^{35}$ la carencia de un debate doctrinal sobre estas materias, que de existir posibilitarían la formulación de reformas y avances consistentes, posiblemente de carácter global.

Ya en 2014, la citada profesora, advertía como carencia de la modernización del Derecho societario la fragmentación que lo ha inundado desde sus inicios legislativos, y como una consecuencia inevitable de ello, las reformas realizadas no han logrado atender los aspectos sustantivos más necesitados de cambios y modernización. De este modo, los cambios efectuados podrían calificarse como cosméticos si observamos las necesidades que verdaderamente plantea la modernización del Derecho

\footnotetext{
${ }^{33}$ VÁsquez, María Fernanda, “¿Hacia dónde va el derecho societario?: un análisis desde el derecho comparado y una propuesta preliminar para el Derecho chileno", Revista Chilena de Derecho, 2015, Vol. 42, No 1, p. 56.

${ }^{34}$ VÁsquez, María Fernanda, Sociedades. Comerciantes, empresas, grupos de empresas y otros sujetos del Derecho Comercial, Thomson Reuters, Santiago, 2015, 1a edición, p. 832.

${ }^{35}$ VÁsquez, María Fernanda, "Estado actual del Derecho societario en Chile: pasos que debemos dar en pos de su modernización" en VÁsquez, M.F.; EmbiD I., J.M. (Dirs), Modernización del Derecho de sociedades, Thomson Reuters, Santiago, 2015, $1^{\text {a }}$ edición, p. 208.
} 
societario. Señalaba, y aún en 2021 se puede reiterar que esta labor aún no se ha realizado. ${ }^{36}$

Concluimos que, en conjunto, el coste económico y jurídico del empleo de página web corporativa u otros medios de comunicación electrónicos para convocatoria de junta general quedan compensados con las ventajas que aportan al funcionamiento de las sociedades de capital.

Quizá la razón de la escasa utilización de los mismos responda al desconocimiento de sus ventajas, el funcionamiento rutinario de las sociedades de capital y falta de colaboración por parte de los socios. Asumamos quienes conocemos sus ventajas la responsabilidad de dar a conocer la utilidad de las nuevas tecnologías aplicadas al Derecho societario, tanto desde el mundo académico como profesional.

\section{BIBLIOGRAFÍA CITADA}

\section{a) Doctrina}

Comisión Especial para el Fomento de la Transparencia y la Seguridad en los Mercados Financieros y las Sociedades Cotizadas (Eds.), "Informe de la Comisión Especial para el Fomento de la Transparencia y la Seguridad en los Mercados Financieros y las Sociedades Cotizadas (Informe Aldama)", Gobierno de España, Madrid, 2003.

FernándeZ, Luis; Vicent, Francisco, "Internet y el Derecho de sociedades. Una primera aproximación", Revista de Derecho Mercantil, 2000, No 237, pp. 915-1002.

Jequier, Eduardo, Curso de Derecho Comercial, Thomson Reuters, Santiago, 2016, Tomo II, Vol. 2, $2^{\mathrm{a}}$ edición.

JORQUERA, Lis, "La web corporativa como instrumento de relación de las sociedades mercantiles con socios y terceros. Aspectos prácticos", Diario La Ley, 2013, $\mathrm{N}^{\mathrm{o}} 8186$.

Nieto, Ubaldo, "Convocatoria de junta general a través de la web social”, Actualidad Jurídica Aranzadi, 2012, № 836.

Olavarría, Julio, Manual de Derecho Comercial, Clarase, Barcelona, 1970, $3^{\text {a }}$ edición.

${ }^{36}$ VÁsquez, María Fernanda, "Intentos modernizadores en el derecho societario chileno: análisis de las leyes 20.494 y 20.659”, Revista de Derecho Universidad Católica del Norte, 2014, Vol. 21, №. 1 , pp. 353-384. 
Pérez, Aránzazu, "De nuevo sobre la convocatoria de junta general de sociedades de capital tras la reciente reforma del artículo 173 de la Ley de Sociedades de Capital", Diario La Ley, 2012, No 7914.

PÉrEz, Valerio, "Reflexión crítica sobre la incidencia de las nuevas tecnologías en el Derecho de sociedades", Conferencia, Colegio Notarial de Madrid, 14 de febrero de 2008.

SAndoval, Ricardo, Derecho comercial. Tomo I, Editorial Jurídica de Chile, Santiago, 2015.

VÁsquez, María Fernanda, Sociedades. Comerciantes, empresas, grupos de empresas y otros sujetos del Derecho Comercial, Thomson Reuters, Santiago, 2015, 1a edición.

VÁsquez, María Fernanda, "Intentos modernizadores en el derecho societario chileno: análisis de las leyes 20.494 y 20.659", Revista de Derecho Universidad Católica del Norte, 2014, Vol. 21, Nº. 1, pp. 353-384.

VÁsquEZ, María Fernanda, ¿¿Hacia dónde va el derecho societario?: un análisis desde el derecho comparado y una propuesta preliminar para el Derecho chileno", Revista Chilena de Derecho, 2015, Vol. 42, No 1.

VÁsquez, María Fernanda, "Estado actual del Derecho societario en Chile: pasos que debemos dar en pos de su modernización" en VÁsQuez, M.F.; EMBID I., J.M. (Dirs), Modernización del Derecho de sociedades, Thomson Reuters, Santiago, 2015, $1^{\text {a }}$ edición.

\section{b) Fuentes electrónicas}

Colegio de Registradores de EspaÑa (Eds.), "Páginas web corporativas inscritas. Informe de estadística mercantil”, 2019, documento .html disponible en línea: https://www.registradores.org/estaticasm/Estadistica/2019/septiembre/ paginas/dominios_inscritos.htm (Consultada: 7 de noviembre 2019).

Colegio de Registradores de España (Eds.), "Constituciones de sociedades. Informe de estadística mercantil", 2019, documento .html disponible en línea: https:// www.registradores.org/estaticasm/Estadistica/2019/septiembre/paginas/ constituciones.htm (Consultada: 7 de noviembre 2019).

Superintendencia de Valores y Seguros, "Informe Final Fortalecimiento de Estándares de Gobierno Corporativo de las Sociedades Anónimas Abiertas", 2014, disponible en línea: http:/www.cmfchile.cl/portal/principal/605/ articles-20924_doc_pdf.pdf(Consultada: 7 de noviembre 2019)

\section{c) Legislación citada}

Ley 18.046, Ley sobre Sociedades Anónimas.

Ley 20.382, introduce perfeccionamientos a la normativa que regula los gobiernos corporativos de las empresas.

Decreto Supremo n 702 de 2011, del Ministerio de Hacienda, Nuevo Reglamento 
de las Sociedades Anónimas, aplicable a las sociedades anónimas reguladas por la Ley $\mathrm{N}^{\circ} 18.046$.

Norma de Carácter General CMF N ${ }^{\circ} 450$, de 17 de noviembre de 2020.

Oficio Circular $n^{\circ} 599$ de la Superintendencia de Valores y Seguros, de 15 de abril de 2010.

Real Decreto 1784/1996, de 19 de julio de 1996, por el que se aprueba el Reglamento del Registro Mercantil (España).

Real Decreto-ley 13/2010, de 3 de diciembre de 2010, sobre actuaciones en el ámbito fiscal, laboral y liberalizadoras para fomentar la inversión y la creación de empleo (España).

Ley 25/2011, de 1 de agosto de 2011, de reforma parcial de la Ley de Sociedades de Capital y de incorporación de la Directiva 2007/36/CE, del Parlamento Europeo y del Consejo, de 11 de julio, sobre el ejercicio de determinados derechos de los accionistas de sociedades cotizadas (España).

Ley $1 / 2012$, de 22 de junio de 2012, de simplificación de las obligaciones de información y documentación de fusiones y escisiones de sociedades de capital (España).

Directiva (UE) 2019/1151 sobre la utilización de herramientas y procesos digitales en el ámbito del Derecho de sociedades (Unión europea).

Real Decreto Legislativo 1/2010, de 2 de julio, por el que se aprueba el texto refundido de la Ley de Sociedades de Capital (España). Real Decreto-ley $5 / 2021$, de 12 de marzo, de medidas extraordinarias de apoyo a la solvencia empresarial en respuesta a la pandemia de la COVID-19.

\section{d) Jurisprudencia citada}

Audiencia Provincial de Zaragoza (Sección 5a), nº 114/2011, de 16 de febrero de 2011 (España).

Tribunal Supremo, Sala de lo Civil, Sección $1^{\mathrm{a}}$, de 13 de febrero de 2006, $\mathrm{n}^{\mathrm{o}}$ 95/2006 (España). 